\title{
Durability enhancements using fabric formwork
}

\section{John Orr}

Lecturer in Sustainable Construction, Department of Architecture and Civil Engineering, University of Bath, Bath, UK

Antony Darby

Reader in Structural Engineering, Department of Architecture and Civil Engineering, University of Bath, Bath, UK
Timothy Ibell

Professor of Civil Engineering, Department of Architecture and Civil Engineering, University of Bath, Bath, UK

Mark Evernden

Lecturer in Structural Engineering, Department of Architecture and Civil Engineering, University of Bath, Bath, UK

By replacing conventional concrete moulds with flexible sheets of permeable fabric, the construction of optimised concrete elements that provide material savings of up to $40 \%$ when compared with an equivalent strength prismatic member is possible. This paper details the results of recent tests undertaken at the Building Research Establishment Centre for Innovative Construction Materials at the University of Bath that demonstrate significant additional durability advantages for fabric-cast concrete. Using accelerated test methods, $50 \%$ average reductions in both the non-steady state chloride diffusion coefficient and carbonation coefficients were found when comparing concrete samples cast against permeable and impermeable surfaces. Sorptivity, surface hardness and scanning electron microscopy tests demonstrate further beneficial changes in the fabric-cast concrete. The combined results demonstrate that fabric formwork may be used to create structures optimised for strength and durability.

\section{Notation}

$B_{j} \quad$ coefficient of carbonation for formwork type $j$

$C_{a, j} \quad$ depth of carbonation for formwork type $j$ at time $a(\mathrm{~mm})$

$C_{\mathrm{i}} \quad$ initial chloride content (\% by mass of concrete)

$C_{i, j} \quad$ depth of carbonation for formwork type $j$ at time $i(\mathrm{~mm})$

$C_{\mathrm{r}} \quad$ reference chloride concentration (0.05 mass $\left.\%\right)$

$C_{\mathrm{s}} \quad$ calculated chloride content at exposed surface (\% by mass of concrete)

$C_{x, t} \quad$ chloride content measured at depth $x$ and exposure time $t$ (\% by mass of concrete)

$D_{\text {nss }} \quad$ non-steady state chloride diffusion coefficient $\left(\mathrm{m}^{2} / \mathrm{s}\right)$

$K_{\text {Cr }} \quad$ chloride penetration parameter

$t_{a} \quad$ time of exposure in carbonation chamber (days)

$t_{\mathrm{i}} \quad$ time of exposure to atmospheric conditions (days)

$\eta \quad$ correlation factor between accelerated test conditions and in-situ results (dimensionless)

\section{Permeable formwork}

\section{Controlled permeability formwork (CPF)}

$\mathrm{CPF}$ systems (Figure 1) rely primarily on three mechanisms to remove air and water from the concrete - dynamic fluid pressures from vibration (ACI, 1981), hydrostatic pressure in the concrete and suction from the formwork system itself (Price, 2000). The advantages of permeable formwork include

- fewer blowholes

- improved surface hardness, tensile strength and abrasion resistance

reduced water absorption and permeability

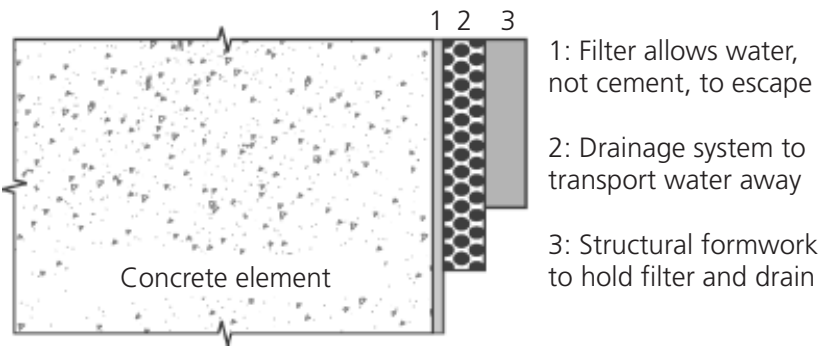

Figure 1. Controlled permeability formwork (after Price (2000))

reduced rates of carbonation, chloride ingress and oxygen diffusion

- improvements in freeze-thaw resistance (Price, 2000).

\section{Fabric formwork}

As an alternative to CPF systems, fabric formwork introduces the possibility of providing similar durability enhancements to the cast concrete, while at the same time facilitating optimisation of the structural form (Orr et al., 2011). The great advantage of fabric formwork over CPF is that the fabric acts as both a permeable liner and formwork to the concrete.

Such an approach is desirable for a number of reasons. Cement accounts for a large proportion of the world's raw material expenditure, reaching nearly $33 \%$ of the total in 2008 (USGS, 2008). Although concrete has a relatively low embodied energy (Hammond and Jones, 2008) its rate of consumption means that cement manufacture alone is estimated to account for some $5 \%$ of global carbon dioxide emissions (WRI, 2005). 
Magazine of Concrete Research

Volume 65 Issue 20
Durability enhancements using fabric

formwork

Orr, Darby, Ibell and Evernden
Research has shown that reductions in embodied carbon can be achieved for concrete structures simply by replacing conventional orthogonal moulds with light-weight, high-strength, low-cost sheets of fabric (Orr et al., 2011). This flexible formwork not only provides environmental benefits, but can also provide new architectural forms for concrete structures (Figure 2).

Less work has focused on the changes in concrete properties that arise as a result of casting concrete into permeable fabric formwork. Delijani (2010) demonstrated improvements in surface hardness for fabric-cast concrete and confirmed that permeable fabric formwork systems provide surface, rather than global, increases in strength. Chandler and Pedreschi (2007) qualitatively noted that concrete cast into a fabric mould gives a much improved surface finish (Figure 3). The potential for fabric formwork to provide a construction method for optimised structures with improved durability is shown in this paper.

\section{Durability study}

Five test series comparing the durability of concrete cast against permeable and impermeable formwork are described in this paper and summarised in Table 1.

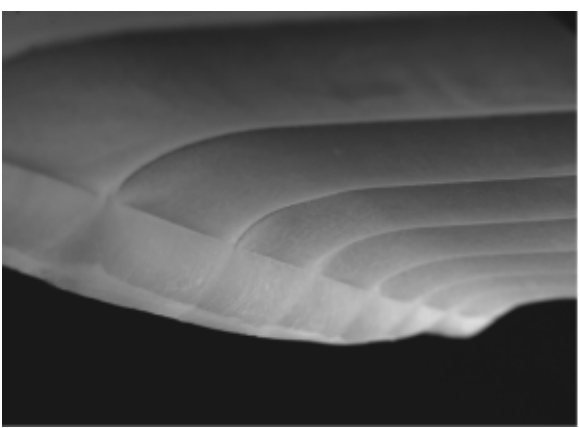

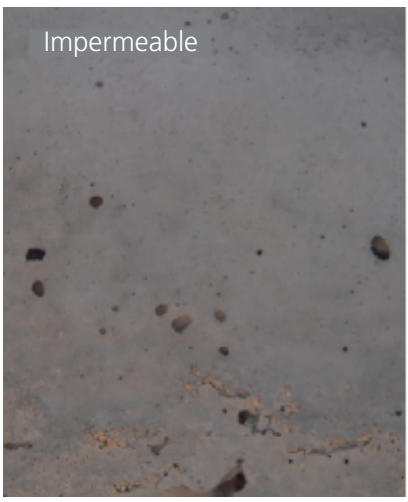

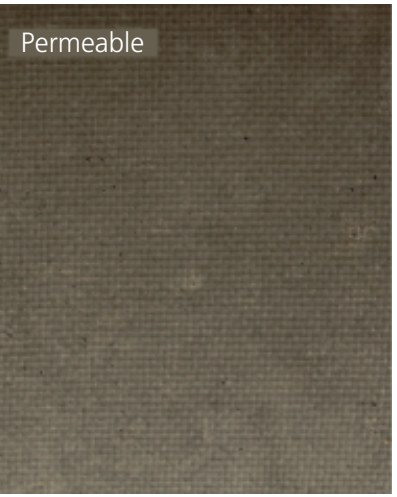

Figure 3. Identical concrete cast in impermeable and permeable moulds

\section{Materials}

The same concrete mix (Table 2) and fabric (Table 3) was used in all tests. The concrete mix used had an average cube compressive strength of $44 \mathrm{MPa}$ at 28 days.

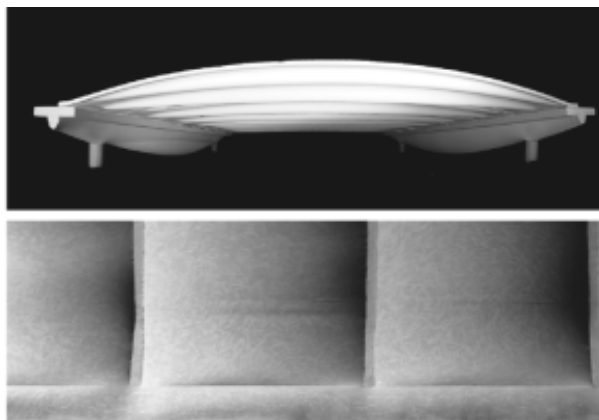

Figure 2. Fabric-formed concrete elements

\begin{tabular}{ll}
\hline Series & Description \\
\hline 1 & Accelerated carbonation tests: 30 specimens; 240 tests \\
2 & Chloride resistance of concrete: 4 cylindrical specimens; 36 tests \\
3 & Surface hardness: 4 specimens \\
4 & Sorptivity testing: 12 concrete cylinders \\
5 & SEM analysis: 7 samples cut from $150 \times 150 \times 350 \mathrm{~mm}$ concrete prisms
\end{tabular}

Table 1. Test series summary

\begin{tabular}{lccc}
\hline \multirow{2}{*}{ Cement (CEM Ilbv): kg } & $\begin{array}{c}\text { Tap } \\
\text { water: } \mathrm{kg}\end{array}$ & & \multicolumn{2}{c}{ Aggregate: $\mathrm{kg}$} \\
\cline { 3 - 4 } & & $0-5 \mathrm{~mm}$ & $5-10 \mathrm{~mm}$ \\
\hline 450 & 180 & 531 & 1239
\end{tabular}

Table 2. Concrete mix design 


$\begin{array}{lcc}\text { Name } \quad \text { Material } & \begin{array}{c}\text { Tensile strength } \\ \text { (warp and weft): } \mathrm{kN} / \mathrm{m}\end{array} & \begin{array}{c}\text { Elongation } \\ \text { (warp and weft): \% }\end{array}\end{array}$

\begin{tabular}{llll}
\hline Marine geotextile 1100 dtex polyester & 54 & 25 & 423 \\
Table 3. Fabric properties & & &
\end{tabular}

\section{Series 1: carbonation}

Steel reinforcement in concrete structures is primarily protected from corrosion by the alkalinity of concrete. Carbonation of the concrete mix, precipitated predominantly by the presence of carbon dioxide in the atmosphere, reduces the alkalinity through the conversion of calcium hydroxide in the cement paste to calcium carbonate and water. Carbonation occurs primarily by gaseous diffusion through air-filled pores, as described by Fick's law (Steffens et al., 2002).

To determine the resistance of concrete to carbonation, accelerated testing can be undertaken by exposing samples to conditions of elevated carbon dioxide. Test methods vary from $1 \%$ (BSI, 2004) to $100 \%$ carbon dioxide concentration (Dunster, 2000). By comparison, atmospheric carbon dioxide concentration is approximately $0 \cdot 039 \%$ by volume (Tans, 2010).

To determine and verify the extent of improvements in resistance to carbonation of fabric-formed concrete, $100 \mathrm{~mm}$ cubes with two test faces (one with permeable and one with impermeable formwork, as shown in Figure 4) were cast and tested using the following accelerated carbonation method.

Fifteen cube specimens were cured first in water at a temperature of $20 \pm 2{ }^{\circ} \mathrm{C}$ for 14 days and then in air at a relative humidity (RH) of $50 \pm 5 \%$ and temperature of $20 \pm 2^{\circ} \mathrm{C}$ for a further 14 days. Four sides of the cube were coated in paraffin and the two test surfaces were then exposed to an atmosphere containing $4 \%$ carbon dioxide $(\mathrm{RH}=60 \pm 5 \%)$ in a carbonation chamber. Dunster (2000) suggests that under such a regime, 1 week in the carbonation chamber is analogous to 12 months of indoor exposure to atmospheric carbon dioxide.

Carbonation depths were recorded at 7, 14, 28, 90 and 180 days exposure by splitting each specimen into two and spraying the exposed surfaces with a phenolphthalein solution. Carbonation depth measurements at each testing stage are summarised in Figure 5. Carbonation depths from the face cast against fabric (permeable surface) and the face cast against the impermeable surface were recorded at four points (Figure 6).

\section{Results}

After 180 days, the permeable fabric-cast face had a total carbonation depth of $6.7 \mathrm{~mm}$, while the impermeably cast face had $12.7 \mathrm{~mm}$ carbonation. The full test results are plotted against the square root of time in Figure 5, since models for the prediction of concrete carbonation depth with age (Hunkeler,

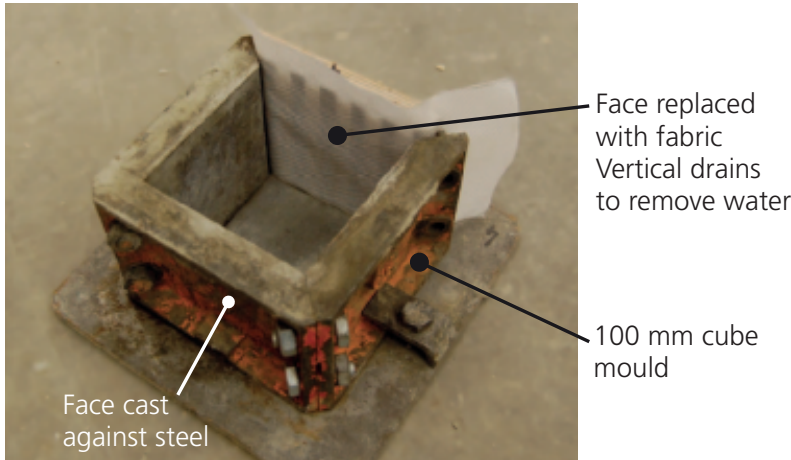

(a)

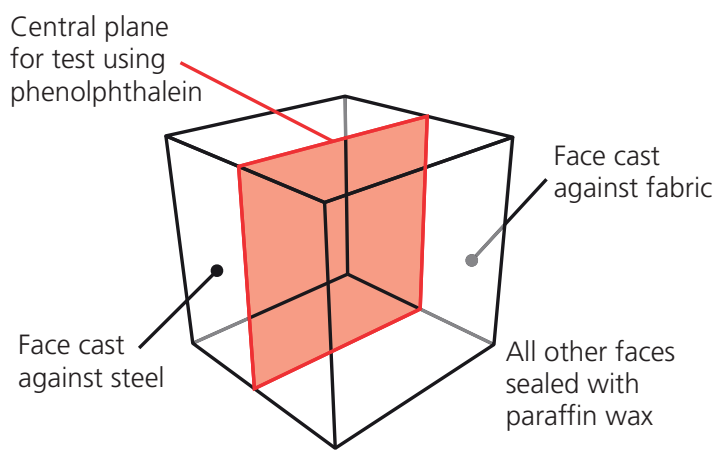

(b)

Figure 4. (a) Modified cube mould; (b) Cubes for carbonation depth measurement

2005; Liang et al., 2002; Papadakis et al., 1991) can be summarised by

1. $C_{a, j}=B_{j}\left(t_{a}\right)^{0 \cdot 5}$

where $C_{a, j}$ is the depth of carbonation in mm for formwork type $j$ at time $a, B_{j}$ is the coefficient of carbonation for formwork type $j$ and $t_{a}$ is the time of exposure in the carbonation chamber $(4 \%$ carbon dioxide) in days. The coefficient of carbonation $B$ is calculated from the test data. Its value encompasses a range of variables that are beyond the scope of the investigation. Steffens et al. (2002) and Saettaa and Vitaliani (2004) proposed further models that incorporate the effects of heat, moisture and gas flows through concrete to provide a more detailed predictive analytical model of the carbonation process. 


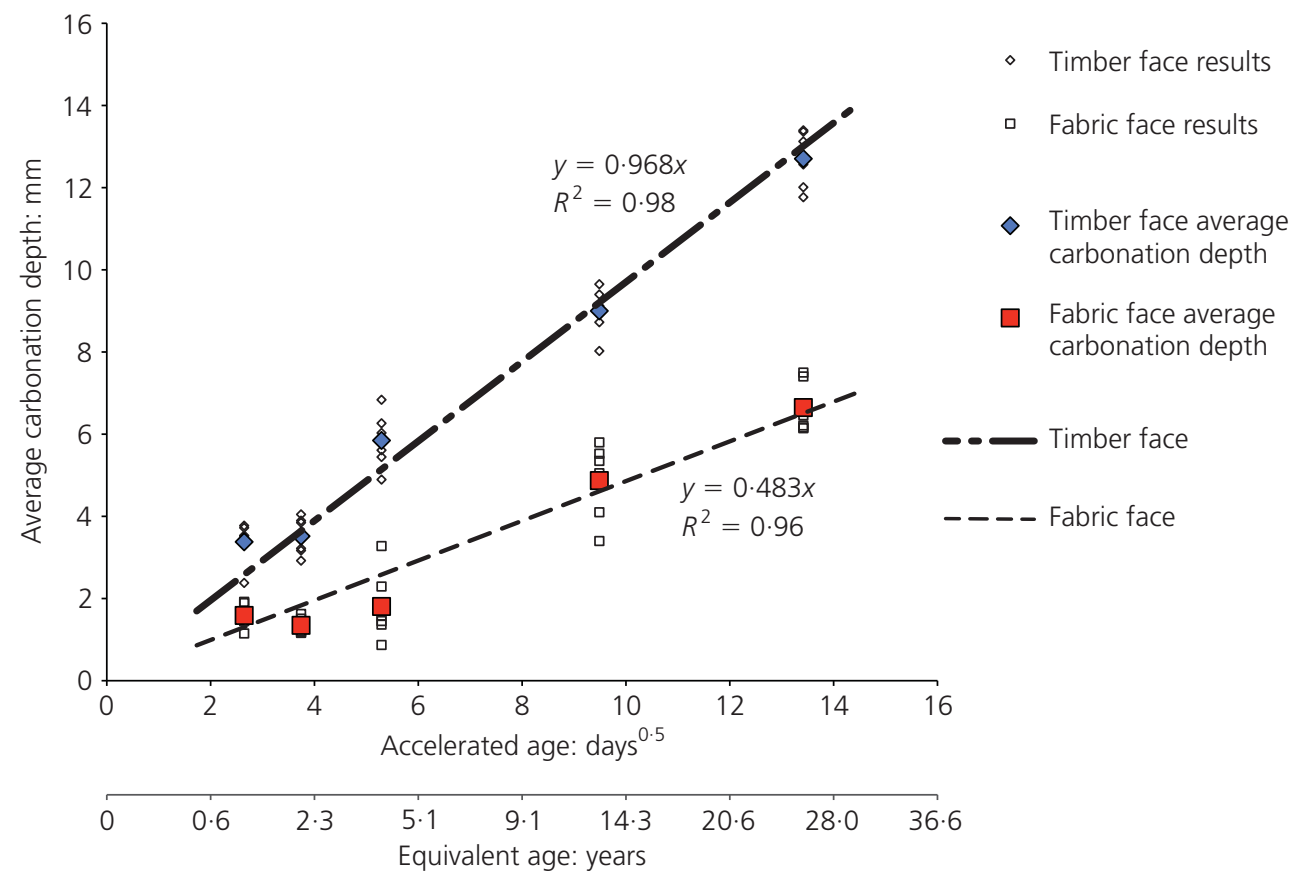

Figure 5. Changes in carbonation depth

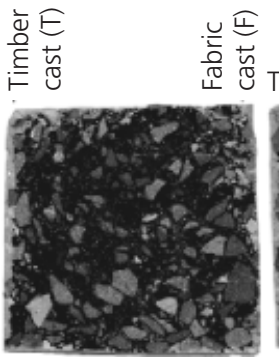

7 days

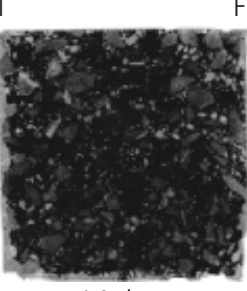

14 days

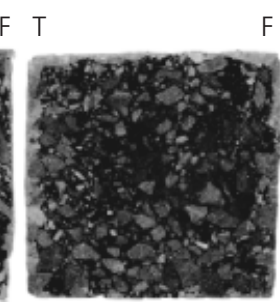

28 days

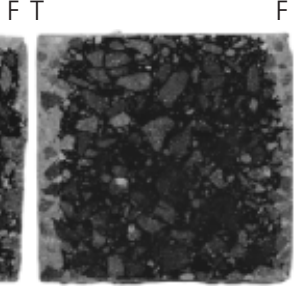

90 days

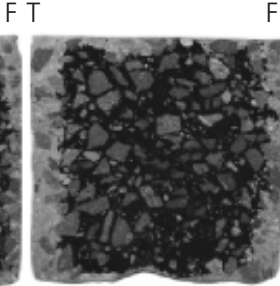

180 days

Figure 6. Carbonation at each testing stage (uncarbonated area shaded dark)

From Figure 5, the coefficient $B$ was calculated by linear interpolation between the test data points. Equations were determined to compare and predict the rate of carbonation in impermeably and permeably cast concrete members. The coefficients of carbonation were calculated as $B_{\text {impermeable }}=0.968$ $\left(R^{2}=0.98\right)$ and $B_{\text {permeable }}=0.483\left(R^{2}=0.96\right)$ by curve fitting against the test data. This represents a reduction in the coefficient of carbonation of $50 \%$ for the fabric (permeable formwork) cast concrete compared with the impermeably cast concrete. The lower coefficient of determination for the fabric-cast concrete test results correlates to a greater variation in carbonation depths between the tests.

Equation 2 was used to estimate carbonation under atmospheric conditions, with the modification factor $\eta$ given by Equation 3 accounting for the accelerated nature of the tests.
2. $C_{i, j}=B_{j}\left(\eta t_{i}\right)^{0 \cdot 5}$

3. $\eta=\frac{\text { test days }}{\text { in situ days }}=\frac{7}{365 \cdot 25}=0 \cdot 019$

in which $C_{i, j}$ is the carbonation (in $\mathrm{mm}$ ) for formwork type $j$ at time $i$ and $t_{\mathrm{i}}$ is the time of exposure to atmospheric conditions (in days).

Predictions can then be made for carbonation depths on each surface type over their service life. It should be noted that work by Kropp and Hilsdorf (1995) suggests that the $t^{0.5}$ method may overestimate carbonation depths over significant time periods as 
the rate of carbonation tends to slow with time. Further work is required to quantify this in the context of fabric formwork.

\section{Discussion}

Accelerated carbonation testing was carried on specially prepared cubes exposed to high concentrations of carbon dioxide for up to 180 days. The results show considerable improvement in resistance to carbonation for the fabric-cast concrete surface.

After 180 days, the fabric-cast surface had a coefficient of carbonation $50 \%$ less than that at the impermeably cast surface. This is comparable to results achieved using CPF reported by Price (2000), but the fabric mould provides the additional benefit of facilitating optimised design. The improved durability of the fabric-cast concrete then potentially allows for reductions in cover distances to be achieved, further reducing concrete volumes and embodied carbon.

Further work is required to determine the influence of the watercement ratio, aggregate-cement ratio, carbon dioxide concentration, temperature and $\mathrm{RH}$ during testing. Testing a range of concrete strengths and fabric types will provide more complete guidance for designers.

The capacity of cement to bind chlorides is also influenced by the degree of concrete carbonation. Carbonated cement pastes were found (Yuan et al., 2009) to have minimal binding capacity, resulting in more free chlorides whose primary impact is to initiate corrosion of internal reinforcement. In addition, reductions in $\mathrm{pH}$ due to carbonation can release previously bound chlorides, giving a doubly negative impact on durability (Yuan et al., 2009). Therefore, the protection afforded against carbonation by a permeable mould further helps to reduce the effects of chloride ingress on the concrete and its reinforcement.

\section{Series 2: chloride ingress}

Chloride ingress has a significant impact on the rate of reinforcement corrosion by destroying the passive oxide layer, reducing the pore water $\mathrm{pH}$, increasing the internal moisture content and increasing electrical conductivity of mass concrete (Hunkeler, 2005). While BS EN 206-1 (BSI, 2000) ensures there is no longer a chloride risk from the concrete mix itself, environmental sources such as de-icing salts remain a threat.

\section{Mechanisms}

Not all chlorides in concrete are available to act as corrosion initiators (Glass and Buenfeld, 2000). Some chlorides are bound to the cement matrix, while others are free and dissolved in interconnected pores (Martin-Perez et al., 2000). A high binding capacity reduces both the rate of chloride ion transport and the amount of free chlorides that are able to initiate steel corrosion (Nilsson et al., 1994). Cement binding also produces Friedel's salt, the structure of which retains chlorides and the formation of which results in a less porous concrete that further retards chloride ingress (Yuan et al., 2009).

\section{Test outline}

The potential for increased chloride resistance in fabric-cast concrete was investigated by chloride ingress tests on $100 \mathrm{~mm}$ diameter cylindrical concrete specimens, with the flat base surface forming the test face, as summarised in Table 4 and illustrated in Figure 7. NordTest method 443 (NordTest, 1995) was followed.

After casting and demoulding, the cylinders were cured for 42 days in laboratory conditions before being cut in half at midheight, with one half providing a reference chloride content and the other acting as the test specimen. Each test specimen was preconditioned by immersion in a saturated calcium hydroxide (lime-water) solution until a constant mass was achieved $(<0 \cdot 1 \%$ change over $24 \mathrm{~h})$ and all faces of the specimen except the test face were coated in wax. The samples were then immersed in a saturated calcium hydroxide solution for a second

\begin{tabular}{llc}
\hline Series & Mould type & $\mathrm{NaCl}$ exposure: days \\
\hline 1 & Permeable & 53 \\
2 & Permeable & 90 \\
3 & Impermeable & 53 \\
4 & Impermeable & 90
\end{tabular}

Table 4. Chloride ingress test details
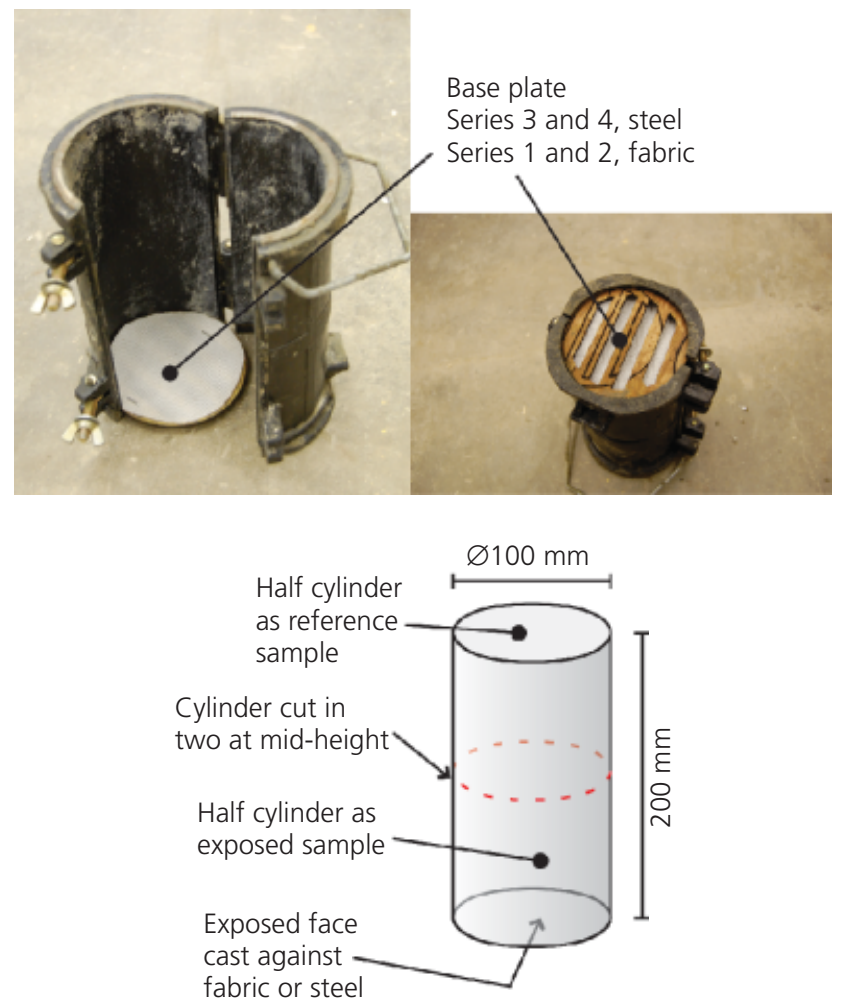

Figure 7. Modified cylinder moulds 
Magazine of Concrete Research

Volume 65 Issue 20
Durability enhancements using fabric

formwork

Orr, Darby, Ibell and Evernden time to achieve a constant mass before being placed in an aqueous solution of sodium chloride $(165 \pm 1 \mathrm{~g} \mathrm{NaCl}$ per $0.001 \mathrm{~m}^{3}$ water at $23 \pm 2^{\circ} \mathrm{C}$ ) for either 53 or 90 days.

After exposure, the cylinders were dried at $105 \pm 5^{\circ} \mathrm{C}$ for $2 \mathrm{~h}$ before being placed in a desiccator. Concrete samples were taken at $1,3,5,7,10,13,16$ and $20 \mathrm{~mm}$ from the exposed surface, with a separate sample collected from the reference cylinder to determine the initial chloride content of the specimen. A depthcontrolled dry cutting disc was used to extract the samples, which were ground by hand to pass a $1 \mathrm{~mm}$ sieve (Figure 8 ).

\section{Results}

The chloride content by mass of each of the collected concrete samples was determined using Volhard's titration as per NordTest 208 (NordTest, 1996). The surface chloride content $\left(C_{\mathrm{s}}\right)$ and the non-steady state chloride diffusion coefficient $\left(D_{\text {nss }}\right)$ were then determined by fitting Equation 4 to the chloride content results by means of a non-linear regression analysis following the method of DD CEN/TS 12390-11 (BSI, 2010). Results for $D_{\text {nss }}$ are given in Table 5 .

$$
C_{x, t}=C_{\mathrm{i}}+\left(C_{\mathrm{s}}-C_{\mathrm{i}}\right)\left[1-\operatorname{erf}\left(\frac{x}{2\left(D_{\mathrm{nss}} t\right)^{0 \cdot 5}}\right)\right]
$$

where $x$ is the depth below the exposed surface to the mid-point of the ground layer (in $\mathrm{m}$ ) and $\operatorname{erf}(z)$ is the error function defined by

5.

$$
\operatorname{erf}(z)=\frac{2}{\sqrt{\pi}} \int_{0}^{z} \exp \left(-u^{2}\right) \mathrm{d} u
$$

\section{Analysis}

The non-steady state chloride diffusion coefficient $D_{\text {nss }}$ was reduced by a maximum of $58.0 \%$ in permeably cast samples at 53 days and by $41.5 \%$ at 90 days (see Table 6 and Figure 9). Such reductions are comparable to those reported by Price (2000).

Further comparisons for the specimens described in Table 4 can be made using the chloride penetration parameter $K_{\mathrm{Cr}}$ (NordTest, 1995), given by Equation 6, the results of which are shown in Table 7.

6. $K_{\mathrm{Cr}}=2\left(D_{\mathrm{nss}}\right)^{0.5} \operatorname{erf}^{-1}\left(\frac{C_{\mathrm{s}}-C_{\mathrm{r}}}{C_{\mathrm{s}}-C_{\mathrm{i}}}\right)$

where $\operatorname{erf}^{-1}$ is the inverse error function again defined by Equation 5.

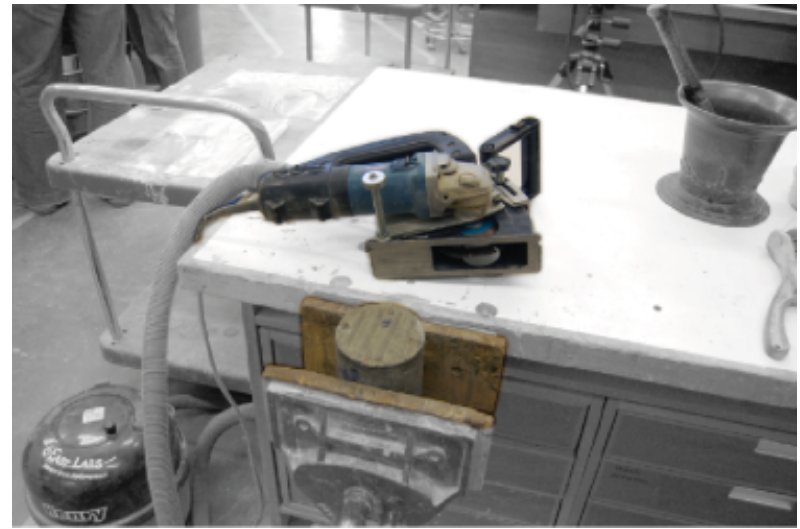

(a)

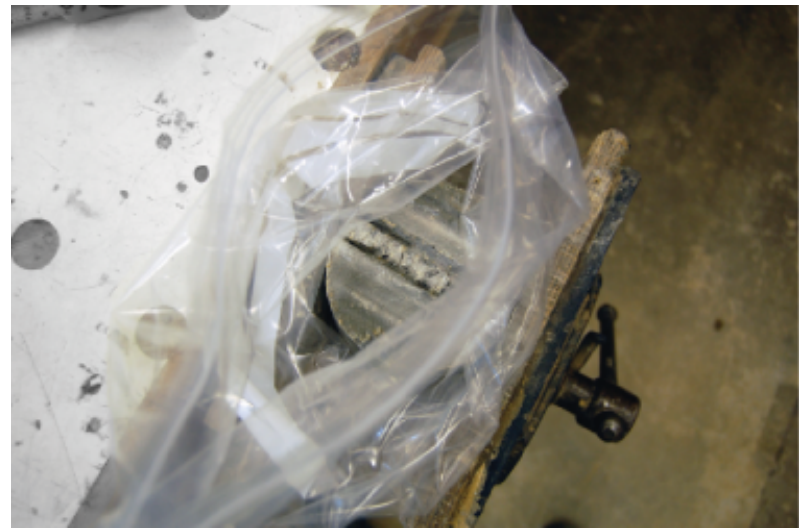

(b)

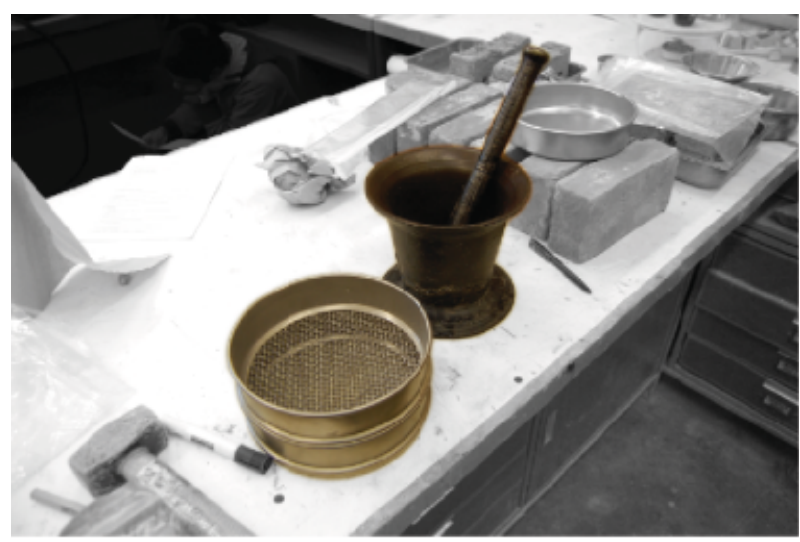

(c)

Figure 8. Concrete sampling procedure: (a) cutting equipment; (b) sample broken by depth; (c) grinding

\begin{tabular}{llccc}
\hline Series & Type & Age: days & $D_{\text {nss }}: \mathrm{m}^{2} / \mathrm{s}$ & $C_{\mathrm{s}}$ \\
\hline 1 & Permeable & 53 & $3.15 \times 10^{-6}$ & 0.52 \\
3 & Impermeable & 53 & $7.55 \times 10^{-6}$ & 0.52 \\
2 & Permeable & 90 & $5.20 \times 10^{-6}$ & 0.56 \\
4 & Impermeable & 90 & $8.88 \times 10^{-6}$ & 0.74
\end{tabular}

Table 5. Results for each test series 


\begin{tabular}{|c|c|c|c|}
\hline \multirow{2}{*}{$\begin{array}{l}\text { Age: } \\
\text { days }\end{array}$} & \multicolumn{2}{|c|}{ Average $D_{\text {nss }}: \mathrm{m}^{2} / \mathrm{s}$} & \multirow{2}{*}{$\begin{array}{l}\text { Reduction when } \\
\text { using fabric-cast } \\
\text { concrete: \% }\end{array}$} \\
\hline & Permeably cast samples & Impermeably cast samples & \\
\hline 53 & $3.15 \times 10^{-6}$ & $7.55 \times 10^{-6}$ & $58 \cdot 2$ \\
\hline 90 & $5 \cdot 20 \times 10^{-6}$ & $8.88 \times 10^{-6}$ & $41 \cdot 5$ \\
\hline \multicolumn{3}{|c|}{ Average reduction in $D_{\text {nss }}$} & 50 \\
\hline
\end{tabular}

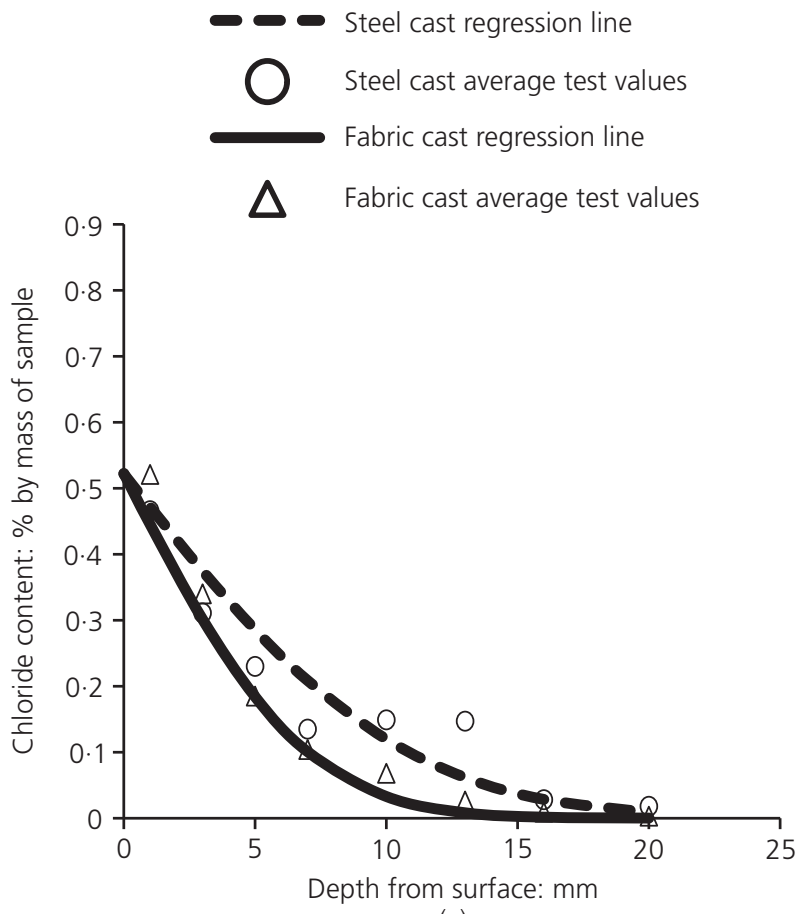

(a)

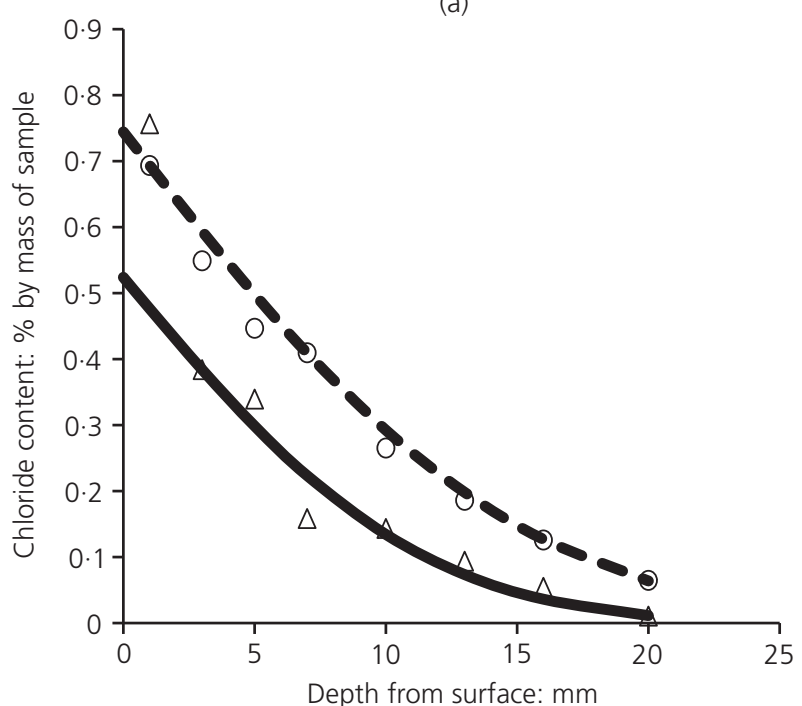

(b)

Figure 9. Average chloride content: (a) comparison of samples 1 and 3 at 53 days; comparison of samples 2 and 4 at 90 days

\section{Discussion}

Concrete cylinders were used to determine the relative resistance to chloride ingress of permeably and impermeably cast surfaces. Analysis of 36 samples collected at incremental depths show average reductions of $50 \%$ in $D_{\mathrm{nss}}$ and $33 \%$ in $K_{\mathrm{Cr}}$ for fabric-cast concrete.

The test method is representative of a submerged concrete structure (CCAA, 2009). While such an approach allows the chloride permeability coefficient to be measured, and has become the standard test method for such situations, it does not consider other processes such as capillary suction, absorption, permeability, migration, adsorption and desorption that occur in nonsubmerged concrete. It is additionally noted that the curing period required by the test method may not be representative of site-cast concrete.

Concerns raised by Tang and Sorenson (2001) over the repeatability and errors associated with chloride penetration tests are noted, as is the limited dataset presented here. Further work is required to generate a larger set and to classify fabric formwork materials based on their permeability to provide a method by which the improvements in resistance to chloride ingress can be predicted.

\section{Sorptivity, surface hardness and SEM tests}

The sorptivity of concrete cast against both permeable and impermeable surfaces in 12 cylinder tests was determined using ASTM C1585 (ASTM, 2004). Compared with the impermeably cast face, the permeably cast concrete was found to have a $6 \cdot 3 \%$ lower surface absorption up to $1 \mathrm{~h}$, a $2.4 \%$ higher absorption up to $6 \mathrm{~h}$, and identical absorption up to 7 days. This suggests fewer large pores (which dominate the rate of initial absorption) (Buyle-Bodin and Hadjieva-Zaharieva, 2002) and a similar amount of small pores (which influence long-term absorption).

The sorptivity results suggest compositional and structural changes to the permeably cast concrete. These changes were preliminarily investigated using scanning electron microscopy (SEM) on cast concrete prisms, as shown in Figure 10. Particle size distributions at the cast face were analysed in four concrete slices using ImageJ software (Ferreira and Rasband, 2011). At the 


\begin{tabular}{|c|c|c|c|}
\hline \multirow{2}{*}{$\begin{array}{l}\text { Age: } \\
\text { days }\end{array}$} & \multicolumn{2}{|c|}{ Average $K_{\mathrm{cr}}: \mathrm{mm} /$ year 0.5} & \multirow{2}{*}{$\begin{array}{c}\text { Reduction when } \\
\text { using fabric-cast } \\
\text { concrete: \% }\end{array}$} \\
\hline & Permeably cast samples & Impermeably cast samples & \\
\hline 53 & $23 \cdot 5$ & $36 \cdot 3$ & $52 \cdot 9$ \\
\hline 90 & $30 \cdot 2$ & $43 \cdot 3$ & $30 \cdot 7$ \\
\hline \multicolumn{3}{|c|}{ Average reduction in $\mathrm{K}_{\mathrm{Cr}}$} & $41 \cdot 8$ \\
\hline
\end{tabular}

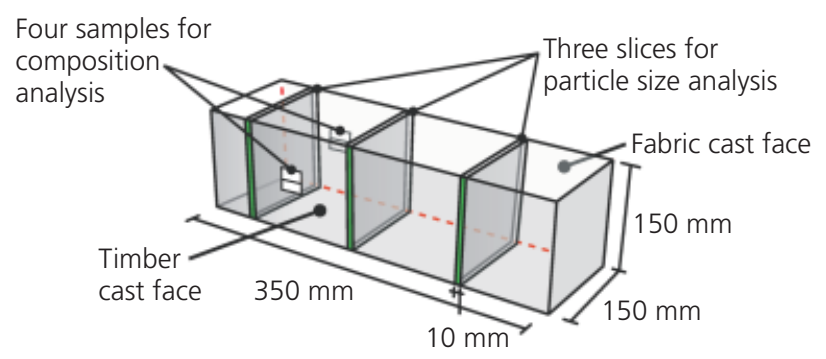

Figure 10. Prisms tested using SEM

permeably cast fabric face, an average reduction in particle size of $31 \%$ compared with the impermeably cast face was recorded.

Compositional changes were also considered at three locations (Figure 10). The permeably cast face was found to have $43 \%$ less silicon and $14 \%$ more calcium (median value by weight $\%$ ) than the impermeably cast face. Lamond (2006) suggests calcium as a good indicator of cement content at the surface, where the influences of non-siliceous aggregate are reduced.

It is proposed that the significant reduction in silica at the permeably cast face arises through a reduction in the presence of larger particles in the surface zone of the permeably cast sample compared with the impermeably cast sample. These changes demonstrate a potential increase in the relative concentration of cement particles at the surface zone. This higher concentration of smaller particles is in turn considered to be linked to the smaller pores recorded in the fabric-cast concrete during sorptivity testing.

Clift et al. (1979) found that the compressive strength of cement mortars could be increased by dewatering to reduce the watercement ratio of each sample. Once the dewatering process had reached equilibrium, the remaining water in menisci around the cement particles acted as sites for calcium-silicate-hydrate (CSH) formation. In the non-dewatered sample, $\mathrm{CSH}$ - which primarily defines strength - could form at any location with water present and was found to result in lower mortar strengths.

A similar effect in the surface of permeably cast concrete may be occurring, but this is not fully clear from the data. Instead of increases in cement content, a change in the presence of calcium hydroxide at the surface of the permeably cast concrete face could be occurring. Such an effect would explain the reductions in silicon described above. Further tests are required to fully determine these changes in permeably cast concrete.

Changes in the surface water-cement ratio may result in improvements in the surface strength of permeably cast concrete. The surface hardness of $100 \times 100 \times 400 \mathrm{~mm}$ concrete prisms with one permeably cast and one impermeably cast face was tested using a Type N Schmidt hammer. At 28, 35, 90, 95 and 180 days, the prisms were fixed securely to a strong floor and tested in 49 locations across each cast face. The results showed an average increase in the surface hardness at the fabric-cast face of $13 \%$ after 35 days (although this reduced to $7 \%$ in the 95 -day test).

\section{Discussion}

By casting concrete into a permeable mould, excess pore water within the concrete is allowed to bleed from its surface, providing the web of advantages illustrated in Figure 11. In summary

- finer material in the surface zone as water is expelled from the cast surface, resulting in a more tortuous surface with fewer interconnected pores

- a greater concentration of cement particles at the surface, giving smaller pores to both constrict the flow of gases through the structure of the concrete and provide sites for the formation of Friedel's salt.

\section{Behaviour}

The dominant process affecting both chloride ingress and carbonation is diffusion. The mechanisms by which permeably cast concrete achieves improved resistance to chloride ingress and carbonation may be described using the semi-empirical, semitheoretical Carman-Kozeny equation (Costa, 2006). Lake (1989) and Xi and Bazant (1999) used this to determine a relationship between porosity (the ratio of voids to total volume), permeability (given by Darcy's law), specific surface area (total pore area divided by the sample volume) and tortuosity (which describes how difficult it is to traverse between two points in comparison to the straight line distance between them and is dependent not on pore size but on their connectedness (Hall and Hoff, 2002)), wherein, for a constant porosity, an increase in the specific 


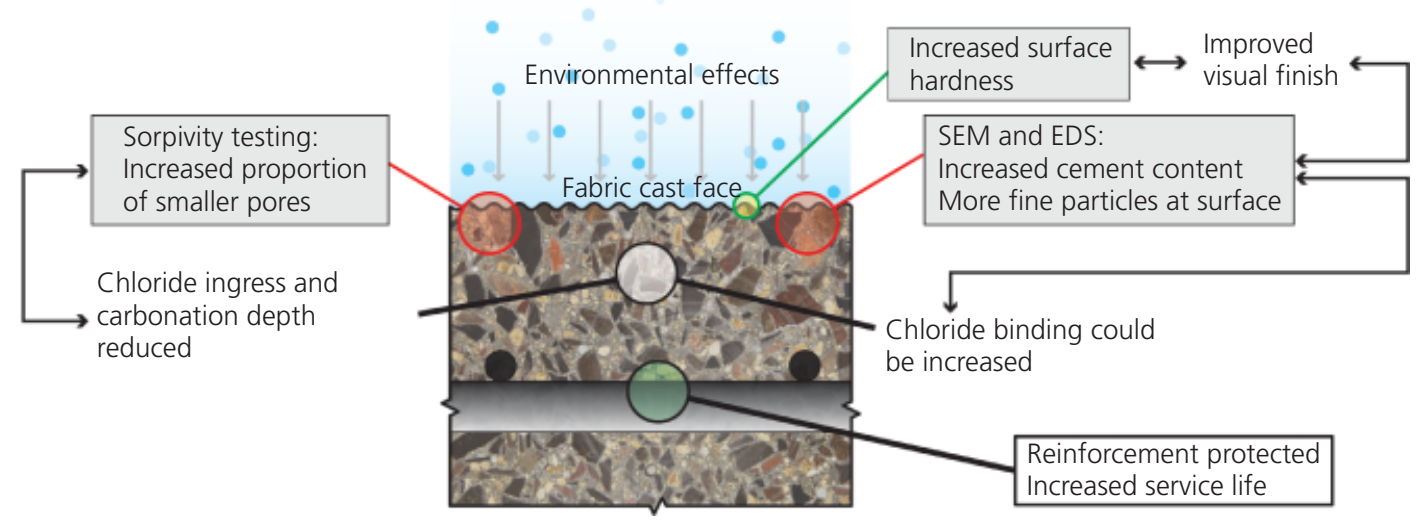

Figure 11. Summary of the proposed effects of casting concrete into fabric formwork in the surface zone

surface area provides a reduction in permeability for the material, as described by

7. $k=\frac{\phi_{1}^{3}}{8 \tau(1-\phi)^{2} s^{2}}$

in which $k$ is permeability, $\phi$ is porosity, $s$ is specific surface area and $\tau$ is tortuosity.

\section{Visual concrete}

Exposed concrete finishes are most often achieved by specifying minimum cement contents to the concrete mix to ensure that sufficient fines reach the surface to reduce the presence of pores and voids. When using fabric formwork, the increased cement content of the surface zone relative to the mass concrete provides these benefits without higher overall cement contents. This avoids the addition of cement not required for strength, while retaining the desired concrete finish (Figure 3). Further work is required to assess the impact of these changes on the potential for shrinkage and cracking at the surface.

\section{Conclusion}

In this work, tests were undertaken to determine how the presence of a permeable fabric mould can affect the durability characteristics of concrete. Accelerated tests for carbonation and chloride ingress showed significant improvements in the fabric-cast samples. Changes at the surface provide a higher strength outer layer, as measured using rebound tests. Combined with a surface free from voids and blowholes, this provides a high-quality visual finish. A reduction in the volume of large pores at the surface, as suggested by sorptivity data, provides a less permeable surface for carbonation and chloride ingress.

The corrosion process is further retarded by increased cement content at the surface (encouraging Friedel's salt formation). Binding of chlorides by this higher cement content further prevents depassivation of the steel. In a similar way, a reduced pore area contributes to the concrete's resistance to carbonation, which helps prevent $\mathrm{pH}$ reductions.

This paper has demonstrated that fabric-cast concrete offers significant advantages for the durability of concrete structures. By providing a permeable mould, an advantageous release of water and air during curing results in a cement-rich surface zone that provides improved resistance to chloride ingress and carbonation when compared with the same concrete cast into an impermeable mould. This may allow designers to reduce cover requirements or specified cement content, facilitating savings in embodied energy above those already achieved by using fabric formwork as a means to construct optimised concrete structures.

The tests presented here represent a significant body of data for the durability of fabric-cast concrete. More extensive test programmes are now required to supplement these results and to determine the optimum fabric that provides ease of construction and durability enhancements.

\section{Acknowledgements}

The authors gratefully acknowledge the support of the Engineering and Physical Sciences Research Council (EPSRC) and Atkins Ltd in this research. They also wish to thank the technical staff in the Department of Architecture and Civil Engineering at the University of Bath for their assistance in preparing the tests described in this paper.

\section{REFERENCES}

ACI (American Concrete Institute) (1981) ACI 309: Behaviour of fresh concrete during vibration. ACI, Farmington Hills, MI, USA.

ASTM (2004) ASTM C1585: Standard test method for measurement of rate of absorption of water by hydrauliccement concretes. ASTM International, West Conshohocken, PA, USA. 
BSI (2000) BS EN 206-1: Concrete - Part 1: Specification, performance, production and conformity. BSI, London, UK.

BSI (2004) BS EN 13295: Products and systems for the protection and repair of concrete structures - Test methods Determination of resistance to carbonation. BSI, London, UK

BSI (2010) DD CEN/TS 12390-11: (Draft for development) Products and systems for the protection and repair of concrete structures - Test methods - Determination of chloride content in hardened concrete. BSI, London, UK.

Buyle-Bodin F and Hadjieva-Zaharieva R (2002) Influence of industrially produced recycled aggregates on flow properties of concrete. Materials and Structures 35(252): 504-509.

CCAA (Cement Concrete and Aggregates Australia) (2009) Chloride Resistance of Concrete. CCAA, Sydney, Australia. Chandler A and Pedreschi R (2007) Fabric Formwork. RIBA, London, UK.

Clift R, Grace JR and Weber ME (1979) Bubbles Drops and Particles. Academic Press, New York, NY, USA.

Costa A (2006) Permeability-porosity relationship: a reexamination of the Kozeny-Carman equation based on a fractal pore-space geometry assumption. Geophysical Research Letters 33(2): 1-5.

Delijani F (2010) The Evaluation of Changes in Concrete Properties due to Fabric Formwork. MSc thesis, University of Manitoba, Winnipeg, MB, Canada.

Dunster AM (2000) Accelerated Carbonation Testing. BRE, London, UK.

Ferreira T and Rasband W (2011) ImageJ User Guide. National Institutes of Health, Bethesda, MD, USA.

Glass GK and Buenfeld NR (2000) The influence of chloride binding on the chloride induced corrosion risk in reinforced concrete. Corrosion Science 42(2): 329-344.

Hall C and Hoff WD (2002) Water Transport in Brick, Stone and Concrete. Spon, London, UK.

Hammond GP and Jones $\mathrm{Cl}$ (2008) Embodied energy and carbon in construction materials. Proceedings of the Institution of Civil Engineers - Energy 161(2): 87-98, in press.

Hunkeler F (2005) Corrosion in reinforced concrete: processes and mechanisms. In Corrosion in Reinforced Concrete Structures (Hans B (ed.)). Woodhead Publishing, Cambridge, UK.

Kropp J and Hilsdorf HK (1995) Performance Criteria for Concrete Durability - a State of the Art Report. Spon, London, UK.

Lake LW (1989) Enhanced Oil Recovery. Prentice Hall, Englewood Cliffs, NJ, USA.

Lamond JF (2006) Significance of Tests and Properties of Concrete and Concrete Making Materials. ASTM International, West Conshohocken, PA, USA.

Liang MT, Qu W and Liang C (2002) Mathematical modeling and prediction of concrete carbonation and its applications. Marine and Science Technology 10(2): 128-135.

Martin-Perez B, Zibara H, Hooton RD and Thomas MDA (2000) A study of the effect of chloride binding on service life predictions. Cement and Concrete Research 30(8): $1215-$ 1223.
Nilsson LO, Sandberg P and Poulsen E (1994) HETEK, A System for Estimation of Chloride Ingress into Concrete, Theoretical Background. Road Directorate, Copenhagen, Denmark.

NordTest (1995) NT Build 443: Concrete, hardened: Accelerated chloride penetration. NordTest, Oslo, Norway.

NordTest (1996) NT Build 208: Concrete, hardened: Chloride content by volhard titration. NordTest, Oslo, Norway.

Orr JJ, Darby AP, Ibell TJ, Evernden MC and Otlet M (2011) Concrete structures using fabric formwork. The Structural Engineer 89(8): 20-26.

Papadakis VG, Vayenas CG and Fardis MN (1991) Fundamental modeling and experimental investigation of concrete carbonation. ACI Materials Journal 88(4): 363-373.

Price WF (2000) Controlled Permeability Formwork. CIRIA, London, UK.

Saettaa AV and Vitaliani RV (2004) Experimental investigation and numerical modeling of carbonation process in reinforced concrete structures. Part I: theoretical formulation. Cement and Concrete Research 34(4): 571-579.

Steffens A, Dinkler D and Ahrens H (2002) Modeling carbonation for corrosion risk prediction of concrete structures. Cement and Concrete Research 32(6): 935-941.

Tang $L$ and Sorenson HE (2001) Precision of the Nordic test methods for measuring the chloride diffusion/migration coefficients of concrete. Materials and Structures 34(242): 479-485.

Tans P (2010) Trends in Carbon Dioxide. See http:// www.esrl.noaa.gov/gmd/ccgg/trends (accessed 11/07/10).

USGS (United States Geological Survey) (2008) Cement Statistics: Historical Statistics for Mineral and Material Commodities in the United States. USGS, Reston, VA, USA.

WRI (World Resources Institute) (2005) Carbon Dioxide Emissions by Source 2005, Earthtrends Data Tables. WRI, Washington, DC, USA.

Xi Y and Bazant ZP (1999) Modeling chloride penetration in saturated concrete. Journal of Materials in Civil Engineering 11(1): 58-65.

Yuan Q, Shi C, Schutter G, Audenaert K and Deng D (2009) Chloride binding of cement-based materials subjected to external chloride environment - a review. Construction and Building Materials 23(1): 1-13.

\section{WHAT DO YOU THINK?}

To discuss this paper, please submit up to 500 words to the editor at www.editorialmanager.com/macr by 1 April 2014. Your contribution will be forwarded to the author(s) for a reply and, if considered appropriate by the editorial panel, will be published as a discussion in a future issue of the journal. 